\title{
Oxidacion electroquimica de plata y cobre en medio acuoso básico y en hidróxidos fundidos
}

\author{
E. M. TEJADA-ROSALES, N. CASAÑ-PASTOR, P. GÓMEZ-ROMERO* \\ Institut de Ciència de Materials de Barcelona (CSIC). Campus de la UAB, 08193 Bellaterra, Barcelona, Spain.
}

\begin{abstract}
En este trabajo se describe la oxidación anódico de electrodos de plata y de cobre en medios básicos. Se han utilizado tanto medios acuosos como hidróxidos fundidos (eutéctico $\mathrm{NaOH} / \mathrm{KOH}$ ). Los procesos de oxidación se han estudiado mediante voltametría cíclica y cronoamperometría, y las fases resultantes han sido caracterizadas por difracción de Rayos X. Los rangos de estabilidad encontrados para cada uno dependen del medio utilizado. Además de óxidos conocidos de cobre y de plata, se ha aislado un nuevo óxido de plata.
\end{abstract}

Palabras clave: Oxidacion electroquimica, hidróxidos fundidos, óxidos de plata y cobre

\section{Electrochemical Oxidation of Silver and Copper in Aqueous Basic Media and in Fused Hydroxide Electrolytes.}

The anodic oxidations of copper and silver electrodes in basic media are reported. Experiments were conducted both in aqueous $\mathrm{NaOH}$ solutions and in a flux of molten $\mathrm{NaOH} / \mathrm{KOH}$ eutectic. The oxidation processes were studied by means of cyclic voltammetry and chronoamperometries and the phases obtained were systematically characterized by $x$-ray diffraction. The ranges of stability of each phase in the different media studied are reported. In addition to known oxides of copper or silver, a new silver oxide was isolated.

Keywords: Electrooxidation, molten hydroxides, silver-copper oxides

\section{INTRODUCTION}

The synthesis of novel metal oxides has relied traditionally upon conventional solid-state reactions at high temperatures. More recently, the advantages of soft-chemistry and low-temperature techniques to yield new metastable compounds have been recognized[1]. But when it comes to the point of preparing oxides with metals in unusual oxidation states further control is necessary. Certain soft chemistry routes have been shown to be well suited for the preparation of oxidized compounds (by in-situ oxidation)[2], but the most obvious choice for a better control of oxidation state is the use of electrochemical techniques.

As part of our continuing effort to probe novel synthetic techniques for the preparation of electroactive oxides we have explored the possibilities of electrochemical reactions and crystallization processes in basic (molten hydroxide) fluxes. This combination allows for the simultaneous control of basicity and electrochemical potential at a relatively low reaction temperature and has been used before for the isolation and crystallization of silver oxides from silver anodes [3-7] or from silver solutions [8-10] and $\mathrm{Cu}$ (III) oxides for instance [11]. Furthermore, molten hydroxide media offer an electrochemicalpotential window large enough to stabilize not only metals but also oxygen in various oxidation states: $\mathrm{O}_{2}^{-1}, \mathrm{O}_{2}^{-2}$ [12-13].

We report here an electrochemical study of the oxidation of silver and copper anodes in aqueous basic media and in molten hydroxide fluxes with different electrolytes added [14]. In addition to the characterization of the oxidation products obtained, this study also contributes to establish the electrochemical stability of the anodes in the strongly basic media used.

\section{EXPERIMENTAL}

The hydroxide used as electrolyte, $\mathrm{NaOH}$, Panreac for analysis $(97 \%)$ and $\mathrm{KOH}$, Merck, ultrapure $(85.90 \%)$ were used as purchased. In the molten hydroxide fluxes $20 \mathrm{~g}$ of the equimolar eutectic $\mathrm{NaOH}$
$(8.32 \mathrm{~g}) / \mathrm{KOH}(11.68 \mathrm{~g})$ were fused at $185^{\circ} \mathrm{C}$ (the theoretical melting point of the mixture is $170^{\circ} \mathrm{C}$ ) in a Teflon crucible exposed to the atmosphere in a sand bath. The hydroxide temperature was controlled with a Teflon-coated thermocouple. The hydroxides were heated for 12 hours before conducting each experiment, in order to assure a reproducible low level of water in the system.

The working electrodes used were silver foil (Goodfellow, $99.95 \%, 1 \mathrm{~cm}^{2}, 0.125 \mathrm{~mm}$ thick) or copper foil (Goodfellow, 99.9\%, $1 \mathrm{~cm}^{2}, 0.125 \mathrm{~mm}$ thick). A platinum wire (Goodfellow, $99.99 \%, 0.5 \mathrm{~mm}$ diameter) was used as counter-electrode, and silver (Goodfellow, $99.95 \%, 0.5 \mathrm{~cm}^{2}, 0.125 \mathrm{~mm}$ thick) or gold foil (Goodfellow, 99.95\%, $0.5 \mathrm{~cm}^{2}, 0.125 \mathrm{~mm}$ thick) were used as pseudo-reference electrodes. These were used both in molten hydroxide and in aqueous solutions for comparison (instead of more conventional $\mathrm{HgO}$ electrodes, which could only be used in the experiments carried out in aqueous media). Some experiments included the addition of $0.02 \mathrm{~g}$ of $\mathrm{CuO}$ (maximum amount soluble in molten hydroxides under the conditions of our experiments) or $0.2 \mathrm{~g}$ of $\mathrm{AgNO}_{3}$ (Panreac, for analysis, 99.8\%).

Electrochemical studies were performed in a three-electrode, one-compartment-cell geometry. An EG\&G PAR 273A and 263A potentiostat were used for these studies.

X-Ray Diffraction patterns of the deposits were measured with a

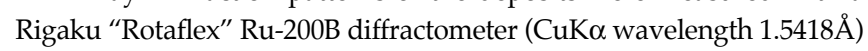

\section{RESULTS AND DISCUSSION}

Electrochemical studies of silver and copper anodes were carried out both in aqueous basic solutions or molten hydroxides. A comparison of the behavior of both metals in those media is presented in this paper. In an attempt to get more easily comparable results, the same reference electrodes used in molten hydroxides (gold and silver) were also used in basic aqueous media instead of the more conventional $\mathrm{HgO}$ reference electrode. Yet, these gold or silver electrodes cannot be 
strictly considered reference electrodes. They have been used in earlier studies as pseudo-reference electrodes [15] and they are certainly useful in cases like the present one, with corrosive molten hydroxide electrolytes, but their lack of a reliable redox couple which could be applied both to aqueous and molten media makes very difficult a direct meaningful comparison of the results in both solvents. On the other hand, the use of these pseudo-reference electrodes has been very valuable for controlling potentials in a particular medium and carrying out electrolysis experiments which could be correlated with the corresponding cyclic voltammogram curves in the same medium.

\subsection{Silver anodes}

Figure 1 shows a cyclic voltammogram of a silver electrode in $3 \mathrm{M}$ $\mathrm{NaOH}$ aqueous solution. Two oxidation and the corresponding two reduction waves can be clearly distinguished. Chronoamperometric oxidations were carried out at each of the oxidation potentials $(600 \mathrm{mV}$ and $900 \mathrm{mV}$ vs. $\mathrm{Au}$ ) for a period of 1-3 hours leading to the formation of smooth dark deposits on the electrode. The resulting compounds were characterized by X-Ray diffraction confirming the presence of cubic $\mathrm{Ag}_{2} \mathrm{O}$ in the first oxidation step and a mixture of $\mathrm{Ag}_{2} \mathrm{O}$ and $\mathrm{AgO}$ in the last one (see figure 2).It should be noted that $\mathrm{AgO}$ is not a $\mathrm{Ag}$ (II) phase but has been shown to contain $A g(I)$ and $A g(I I I)$ by means of neutron diffraction [16] and EXAFS data [17-18] .

Similar experiments were carried out in a mixture of fused $\mathrm{NaOH} / \mathrm{KOH}$. The cyclic voltammogram resulting from this medium is remarkably different from that obtained in aqueous solutions (Figure 3). First of all, in fused hydroxides the redox waves are shifted towards less positive potentials. This must be due to the more basic medium affecting the formation of oxide species. Secondly, in the molten hydroxide CV only a couple of waves are observed, although the oxidation wave shows in some experiments a shoulder, better resolved than in aqueous electrolytes which could correspond to the formation of silver suboxide films. Finally, whereas the $\mathrm{CV}$ in aqueous media shows a self-limiting oxidation process, corresponding to the formation of a passivating layer, the oxidation of silver anodes in molten hydroxides is not self-limited (a complete oxidation of the electrode is possible). This different behavior could be explained in terms of the higher temperature in molten hydroxides (which would facilitate oxygen diffusion through the oxide layer) but also with the different nature of the oxide formed at the electrode surface.

In order to assign the anodic wave to the corresponding process chronoamperometric oxidations of the silver electrodes at $150 \mathrm{mV}$ vs. Au were carried out and the deposits formed were analyzed by X-Ray diffraction (Figure 4). The microcrystalline deposit obtained corresponded to a fairly pure new phase that crystallizes in the orthorhombic system $(a=3.12, b=9.96, c=12.79 \AA)$. Although these lattice parameters are metrically very close to the unit cell of the oxide $\mathrm{Ag}_{2} \mathrm{O}_{3}$ (JCPDS 400909), it should be noted that the diffraction patterns are radically different both concerning the number, position and intensity of the peaks. Indeed, the diffraction pattern of the new phase cannot be assigned to any known compound, and its composition and crystal structure are currently under study. Microcrystals suitable for single-crystal X-Ray diffraction measurements have been obtained although the crystal structure solution seems to be hindered by twinning or pseudosymmetry problems.

\subsection{Copper anodes}

Electrochemical oxidations were carried out on copper electrodes. As for silver electrodes, those studies were made both in basic aqueous solution and molten $\mathrm{NaOH} / \mathrm{KOH}$.

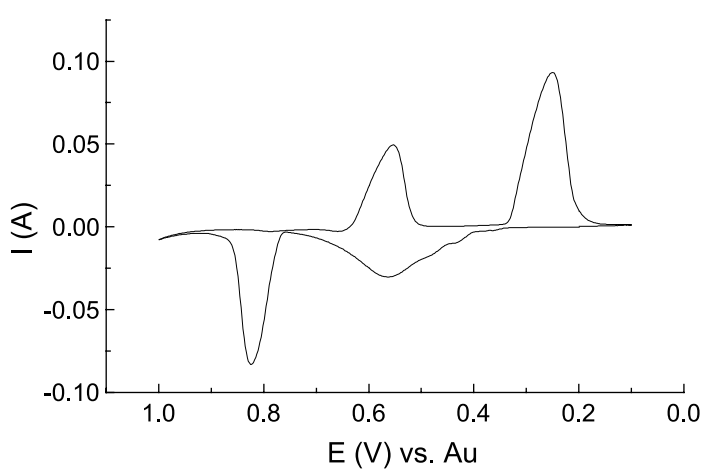

Figure 1. Cyclic Voltammogram of a silver electrode in $3 \mathrm{M} \mathrm{NaOH}$. Scan Rate $20 \mathrm{mV} / \mathrm{s}$, Initial potential: $0.2 \mathrm{~V}$ vs Au. (Oxidation represented as negative current)

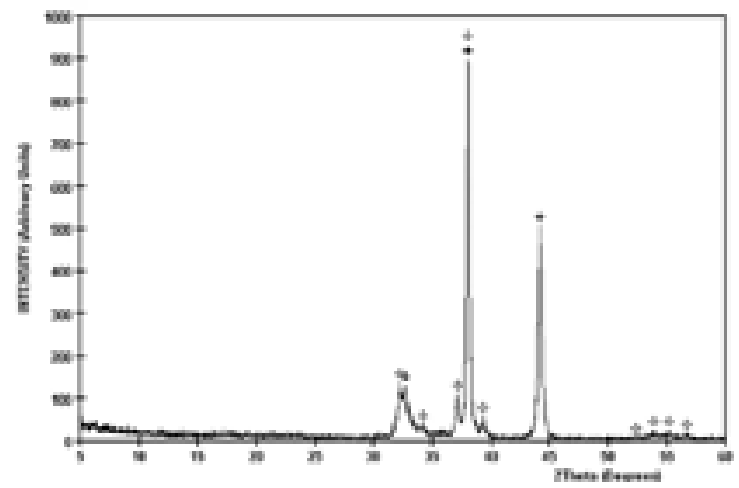

Figure 2. X-Ray diffraction pattern of a silver anode oxidized at $0.9 \mathrm{~V}$ vs $\mathrm{Au}$ in $3 \mathrm{M} \mathrm{NaOH}$. The diffraction patterns of $\mathrm{Ag}_{2} \mathrm{O}$ and $\mathrm{Ag}_{2} \mathrm{O}_{2}$ are superimposed on the one from the metallic silver substrate.

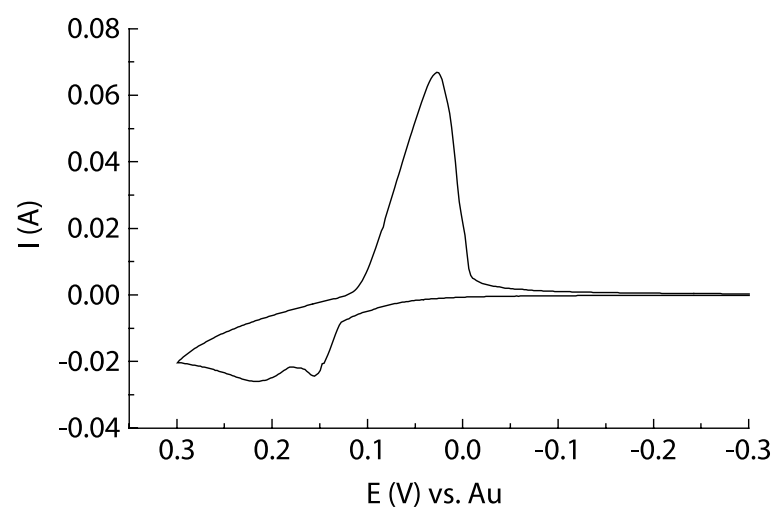

Figure 3. Cyclic Voltammetry of a silver electrode in molten hydroxides. Scan Rate: $20 \mathrm{mV} / \mathrm{s}$. Initial potential: $-0.3 \mathrm{~V}$ vs. Au. (Oxidation: negative current)

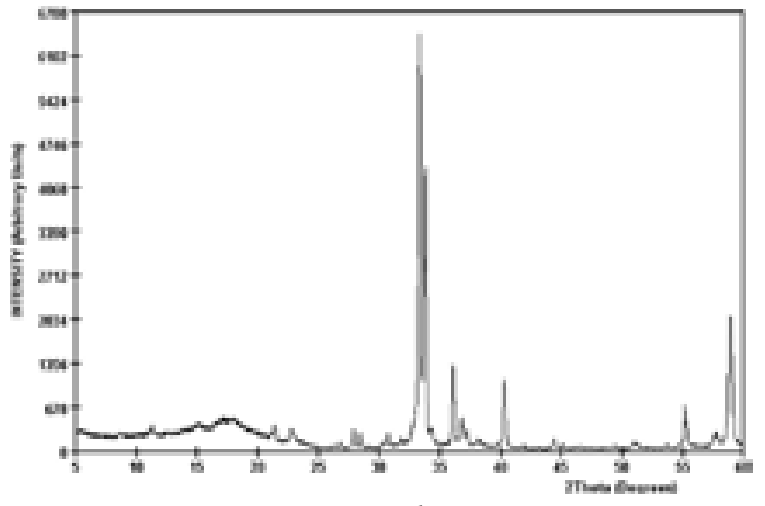

Figure 4. X-Ray diffraction pattern of the solid obtained on a silver electrode after a chronoamperometric oxidation at $150 \mathrm{mV}$ vs $\mathrm{Au}$ in molten $\mathrm{NaOH} / \mathrm{KOH}$ (the pattern was obtained from the powder scrapped from the silver electrode). 
A typical cyclic voltammogram of a copper electrode in $3 \mathrm{M} \mathrm{NaOH}$ (aq) showing basically two redox waves is presented in figure 5 . The first wave at -0.1 Volts vs. Au corresponds to the two-electron oxidation of $\mathrm{Cu}$ directly to $\mathrm{CuO}$, avoiding the formation of $\mathrm{Cu}_{2} \mathrm{O}$ as previously reported [19]. At a potential near $600 \mathrm{mV}$ there is a second smaller wave which we assign to the oxidation to $\mathrm{Cu}(\mathrm{III})$ by comparison with the results obtained in molten hydroxides (see below). So far we have not been able to isolate this oxidized compound. In the same cyclic voltammogram the corresponding reduction waves can also be observed, indicating a reversible nature for the oxidation reactions studied. First the $\mathrm{Cu}$ (III) to $\mathrm{Cu}$ (II) process is detected as a weak wave at 0.6 volts vs. Au. Then, instead of a single two-electron process, two reduction waves only partially resolved are observed, which indicate the possibility of stabilizing $\mathrm{Cu}(\mathrm{I})$ species under this conditions.

Similarly to what happened with silver anodes, the cyclic voltammograms of copper in molten hydroxides are remarkably different from the ones obtained in basic aqueous solutions. In this case, the molten hydroxides medium is very useful for separating the different processes as can be seen in figure 6, where three pair of clear redox waves are resolved. The first oxidation step must correspond to the formation of cuprite $\left(\mathrm{Cu}_{2} \mathrm{O}\right)$. Further oxidation of this system in molten hydroxide gets complicated by dissolution processes not present in aqueous basic media. In this respect, the solubility of $\mathrm{CuO}$ in molten hydroxides, is well known and we have repeatedly ascertained it in our work. Furthermore, a chronoamperometric experiment with a copper anode in molten hydroxides (17 hours at -0.050 vs. Ag ) resulted in the complete dissolution of the anode. Thus, the anodic wave centered at ca. 0.0 Volts shown in figure 6 must correspond to a process of oxidation taking place with simultaneous dissolution of the $\mathrm{Cu}$ (II) oxide formed. The shoulder at lower potentials could correspond to the initial oxidation of $\mathrm{Cu}_{2} \mathrm{O}$ to $\mathrm{CuO}$, which would get dissolved and then a two-electron oxidation could take place $\left(\mathrm{Cu}^{0}\right.$ to $\mathrm{Cu}$ (II) dissolved). The dissolution process is also confirmed by the observation of a blue coloration of the molten flux at this point, which corresponds to well known $\mathrm{Cu}(\mathrm{OH})_{4}{ }^{2-}$ and $\mathrm{Cu}(\mathrm{OH})_{6}{ }_{6}^{4}$ species. Further oxidation of the system at 0.5 Volts vs. $\mathrm{Ag}$ is enough to lead to the formation of $\mathrm{NaCuO}_{2}$, a $\mathrm{Cu}(\mathrm{III})$ compound that has been previously reported.[11, 20-22] In this high oxidation state copper does not form a binary oxide, and $\mathrm{Cu}(\mathrm{III})$ only gets stabilized through the formation of ternary compounds with alkaline metals.[23] The nature of this oxide, which we have also obtained on Pt electrodes from $\mathrm{Cu}$ (II)-containing hydroxide melts has been confirmed by powder $\mathrm{x}$-ray diffraction.

Table I summarizes the electrochemical processes studied, including the values of redox potentials and products isolated in each case.

TABLE I. SUMMARY OF THE OXIDATION AND REDUCTION PROCESSES OBSERVED FOR SILVER AND COPPER ANODES IN STRONG BASIC MEDIA.

\begin{tabular}{|c|c|c|c|c|}
\hline ANODE & MEDIA & $\begin{array}{c}\text { OXIDATION } \\
\text { POTENTIAL }\end{array}$ & $\begin{array}{c}\text { REDUCTION } \\
\text { POTENTIAL }\end{array}$ & PRODUCT \\
\hline $\mathrm{Ag}$ & $\mathrm{NaOH}$ aq. $3 \mathrm{M}$ & $0.56 \mathrm{~V}$ vs. $\mathrm{Au}$ & $0.25 \mathrm{~V}$ vs. $\mathrm{Au}$ & $\mathrm{Ag} / \mathrm{Ag}_{2} \mathrm{O}$ \\
\hline $\mathrm{Ag}$ & $\mathrm{NaOH}$ aq. $3 \mathrm{M}$ & $0.82 \mathrm{~V}$ vs. $\mathrm{Au}$ & $0.56 \mathrm{~V}$ vs. $\mathrm{Au}$ & $\mathrm{Ag}_{2} \mathrm{O} / \mathrm{AgO}$ \\
\hline $\mathrm{Ag}$ & Fused $\mathrm{NaOH} / \mathrm{KOH}$ & $0.15 \mathrm{~V}$ vs. $\mathrm{Au}$ & $0.027 \mathrm{~V}$ vs. $\mathrm{Au}$ & $\mathrm{Ag} / \mathrm{New}$ phase \\
\hline $\mathrm{Cu}$ & $\mathrm{NaOH}$ aq. $3 \mathrm{M}$ & $-0.1 \mathrm{~V}$ vs. $\mathrm{Au}$ & $-0.89 \mathrm{~V}$ vs. $\mathrm{Au}$ & $\mathrm{Cu} / \mathrm{CuO}$ \\
\hline $\mathrm{Cu}$ & $\mathrm{NaOH}$ aq. $3 \mathrm{M}$ & $0.65 \mathrm{~V}$ vs. $\mathrm{Au}$ & $0.59 \mathrm{~V}$ vs. $\mathrm{Au}$ & $\mathrm{CuO} / \mathrm{Cu}(\mathrm{III})($ not isolated $)$ \\
\hline $\mathrm{Cu}$ & Fused $\mathrm{NaOH} / \mathrm{KOH}$ & $-0.36 \mathrm{~V}$ vs. $\mathrm{Ag}$ & $-0.44 \mathrm{~V}$ vs. $\mathrm{Ag}$ & $\mathrm{Cu} / \mathrm{Cu}_{2} \mathrm{O}$ \\
\hline $\mathrm{Cu}$ & Fused $\mathrm{NaOH} / \mathrm{KOH}$ & $-0.015 \mathrm{~V}$ vs. $\mathrm{Ag}$ & $-0.22 \mathrm{~V}$ vs. $\mathrm{Ag}$ & $\mathrm{Cu}_{2} \mathrm{O} / \mathrm{Cu}(\mathrm{II})$ in solution \\
\hline $\mathrm{Cu}$ & Fused $\mathrm{NaOH} / \mathrm{KOH}$ & $0.39 \mathrm{~V}$ vs. $\mathrm{Ag}$ & $0.26 \mathrm{~V}$ vs. $\mathrm{Ag}$ & $\mathrm{Cu}(\mathrm{II})$ in solution $/ \mathrm{NaCuO}_{2}$ \\
\hline
\end{tabular}

A second round of experiments included the addition of copper or silver salts for the oxidation of silver and copper anodes respectively. The purpose of these additions was to test the possibility of obtaining mixed silver copper oxides as the one we recently reported[24]. Nevertheless, the presence of these additional ions in the electrolyte had no significant effect on the oxides obtained.

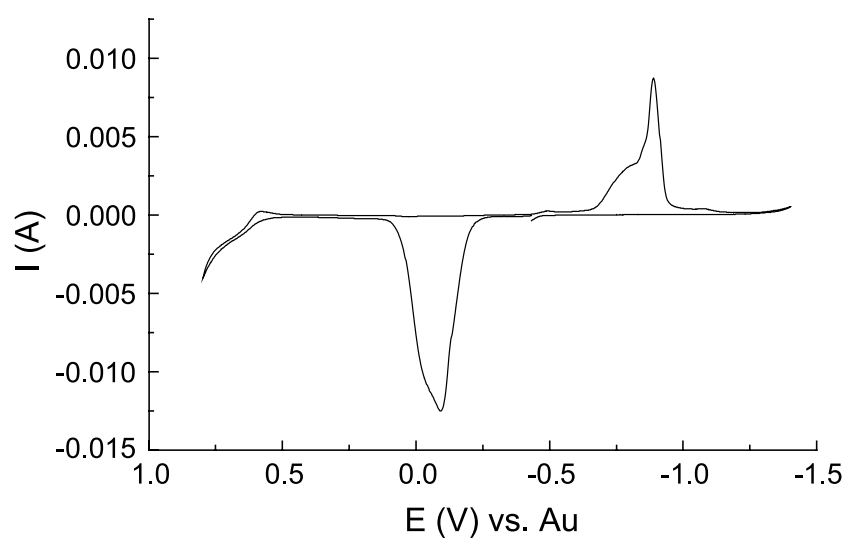

Figure 5. Cyclic Voltammetry of a copper electrode in $3 \mathrm{M} \mathrm{NaOH}$. Scan Rate: $20 \mathrm{mV} / \mathrm{s}$. Initial potential:-0.44V vs Au (Oxidation: negative current)

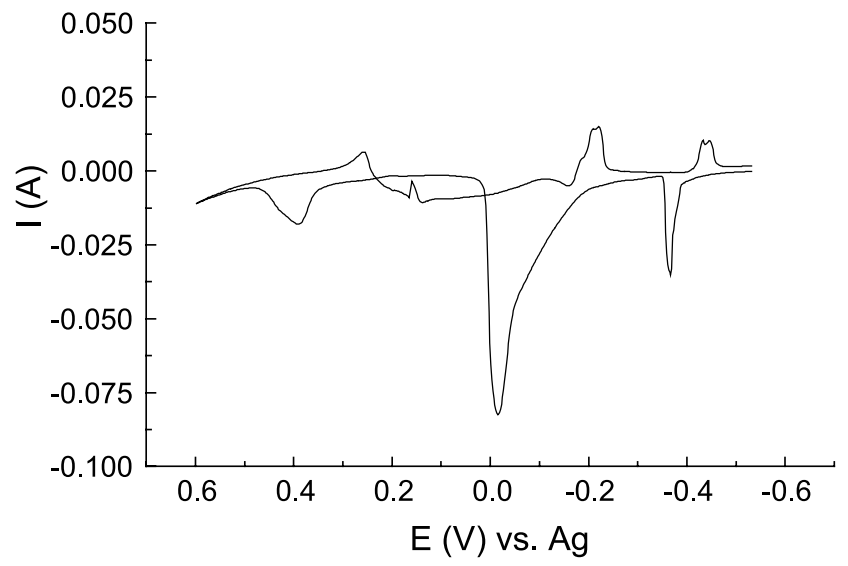

Figure 6. Cyclic Voltammetry of a copper electrode in molten hydroxides. Scan Rate: $5 \mathrm{mV}$ / s. Initial potential:-0.6 V vs Ag (Oxidation: negative current)

\section{CONCLUSIONS}

Electrochemical oxidation of silver or copper anodes in strongly basic media is a straightforward way to prepare films of their oxides. In comparison with more widely studied experiments in basic aqueous media, the use of an eutectic $\mathrm{NaOH} / \mathrm{KOH}$ flux strongly affects the redox behavior of these metals and provides an opportunity to extend the range of phases that can be obtained. This is emphasized by the isolation of an hitherto unknown silver oxide electrocrystallized from that eutectic, the crystal structure of which is presently under investigation.

\section{ACKNOWLEDGMENTS}

This work was funded by the MCyT(Spain), Plan Nacional de Materiales (MAT2001-1709-C04-01 and MAT2002-04529-C03, MAT961057-c02-01and PGC PB98-0491). We also thank the Ministry of Education and Culture (Spain) for a predoctoral fellowship awarded to EMT-R. 


\section{REFERENCES}

1. J. Livage, M. Henry and C. Sánchez, "Sol-gel chemistry of transition metal oxides" Prog. Solid St. Chem., 18 (1988) 259

2. M.R. Palacín, N. Casañ-Pastor and P. Gómez-Romero, "Sol-Gel Synthesis and Simultaneous Oxidation of $L n_{2} \mathrm{Ba}_{2} \mathrm{Cu}_{2} \mathrm{Ti}_{2} \mathrm{O}_{11-\delta}$ " J. Solid State Chem., 138 (1998) 141.

3. J. Gomez Becerra, R. C. Salvarezza, and A. J. Arvia, "The role of a slow phase formation process in the growth of anodic silver oxide layers in alkaline solutions-I. Electroformation of Ag(I) oxide layer" Electrochim. Acta 33 (1988) 1431

4. R. C. Salvarezza, J. Gomez Becerra, and A. J. Arvia "Kinetics and mechanism of the silver (I) oxide to silver (II) oxide layer electrooxidation reaction", Electrochim. Acta 33 (1988) 1753.

5. T. P. Dirkse, "A potentiodynamic study of the electrolytic formation of AgO" Electrochim. Acta 34 (1989) 647.

6. A. N. Mansour, "Evidence for an $\mathrm{Ag}_{4} \mathrm{O}_{3}$ phase of silver oxide" J. Phys. Chem. 94 (1990) 1006

7. T. P. Dirkse, "A potentiostatic study of the electrolytic formation of AgO" Electrochim. Acta 35 (1990) 1445.

8. M. Jansen and P. Fischer, "Eine neue darstellungsmethode für monoklines silber(I,III)oxid (AgO), einkristallzüchtung und röntgenstrukturanalyse" J. Less-Common Met. 137 (1988) 123

9. P. Fischer and M. Jansen, “Cyclovoltammetrische- und Röntgenbeugungsuntersuchungen zur anodischen abscheidung Höherer silberoxide" Solid State Ionics 43 (1990) 61

10. P. Fischer and M. Jansen, "Electrochemical Syntheses of Binary Silver Oxides" Inorg. Synth. 30 (1991) 50

11. T.L. Friedman and A.M. Stacy, "Electrochemistry in Molten Hydroxides: Synthesis of $\mathrm{NaCuO}_{2}$ " J.Solid State Chem. 109 (1994) 203

12. P. Claes and J. Glibert, Molten Salt Techniques, p. 79, D.G. Lovering and R.J. Gale, Eds., Plenum, New York, (1983).

13. J.A.Plambeck, Encyclopedia of Electrochemistry of the Elements Vol, X, (Fused salts) p. 283, a.J. Bard, Ed., Marcel-Dekker, New York, (1976).

14. This work is part of Eva M. Tejada-Rosales, Ph.D. Thesis, “Óxidos complejos de cobre y plata" Universitat Autònoma de Barcelona, 2001

15. B.E. Breyfogle, C-J Hung, M.G. Shumsky, J.A. Switzer, "Electrodeposition of Silver(II) Oxide Films" J.Electrochem. Soc., 143 (1996) 2741.

16. V. Scatturin, P. L. Bellon, A. J. Salkind, "The structure of Silver Oxide Determined by means of Neutron Diffraction" J. Electrochem. Soc. 108 (1961) 819

17. D. Hecht, R. Frahm, H. H. Strehblow, "Quick-Scanning EXAFS in the Reflection Mode as a Probe for Structural Information of Electrode Surfaces with Time Resolution: An in Situ Study of Anodic Silver Oxide Formation" J Phys Chem, 100 (1996) 10831.

18. D. Hecht, P. Borthen, H. H. Strehblow, “An X-ray absorption fine structure study of the initial stages of the anodic oxidation of silver", Surface Sci , 365 (1996) 263.

19. A. H. Moreira, A. V. Benedetti, P. L. Cabot and P. T. A. Sumodjo "Electrochemical behaviour of copper electrode in concentrated sulfuric acid solutions", Electrochim. Acta, 38 (1993) 981.

20. A. De Backer, J. Yperman, B. Ogorevc, G. Tavčar, D. Franco, J. Mullens and L. C. Van Poucke "Multicomponent analysis of sodium cuprate, $\mathrm{NaCuO}_{2-x^{\prime}}$ having a high Cu(III) content" Analytica Chimica Acta, 334, (1996), 103

21. J. Pickardt, W. Paulus, M. Schmalz, R. Schöllhorn, "Crystal growth and structure refinement of $\mathrm{NaCuO}_{2}$ by X-ray and neutron diffraction" J. Solid. State Chem., 89 (1990) 308.

22. N. E. Brese, M. O'Keeffe, R. B. Von Dreele, V. G. Young Jr., “Crystal structures of $\mathrm{NaCuO}_{2}$ and $\mathrm{KCuO}_{2}$ by neutron diffraction" J. Solid. State Chem., 83 (1989) 1.

23. J.K. Burdett, S. Sevov, "Stability of the Oxidation States of Copper" J. Am. Chem. Soc., 117 (1995) 12788

24. P. Gómez-Romero, E.M. Tejada-Rosales, M.R. Palacín, “ $\mathrm{Ag}_{2} \mathrm{Cu}_{2} \mathrm{O}_{3}$ : The First Silver-Copper Oxide" Angew. Chem., 111 (1999) 544. Angew. Chem. Int. Ed. 38 (1999) 524

Recibido: 1.2 .03

Aceptado: 30.11 .03 